\title{
A teoria na prática é outra? \\ Considerações sobre as relações entre teoria e prática em discursos educacionais
}

\author{
JOSÉ SÉRGIO F. DE CARVALHO \\ Universidade de São Paulo
}

Ao professor José Mário Pires Azanha

(in memorian)

\section{APRESENTAÇÃO DO PROBLEMA}

O tema das relações entre teoria e prática na formação de professores é um aspecto particular de um problema amplo e complexo, cujos esforços de elucidação remontam ao início da tradição filosófica. Basta, nesse sentido, lembrar as controversas - ainda hoje instigantes e inspiradoras - posições de Platão (428-348 a.C.) e Aristóteles (384-322 a.C.) acerca do papel do conhecimento teórico da natureza do bem para a formação do homem bom ou virtuoso. $\mathrm{O}$ mal seria, como sugere Sócrates, resultante da ignorância do bem, assim poderia um homem saber o que é o bem e, a despeito disso, agir mal. Qual a natureza das relações entre a capacidade de contemplação do bem, a formulação de uma teoria ética e o desenvolvimento de uma sabedoria prática, que se demonstra em decisões e atos cotidianos? Como se relacionariam, por exemplo, uma teoria da justiça e a capacidade de ser justo ou tomar uma decisão justa? Em outras palavras: Como se relacionam o saber proposicional, que caracteriza qualquer teoria, e o saber fazer que se manifesta na prática, seja ela ética ou docente?

A longevidade e relevância do tema não significam, contudo, que se possa falar em "progresso" no que se refere a seu equacionamento. Pelo contrário, não é 


\section{JOSÉ SÉRGIO F. DE CARVALHO}

\section{A teoria na prática é outra? Considerações sobre as relações entre teoria e prática em discursos educacionais}

O tema das relações entre teoria e prática na formação de professores é um caso particular de um problema amplo e complexo, cujos esforços de elucidação remontam ao próprio início da tradição filosófica. No presente artigo, ele é focalizado a partir de sua incidência em duas modalidades de discurso pedagógico que exerceram grande influência na formação de professores ao longo do século XX: as teorias da educação vinculadas a grandes sistemas filosóficos e os discursos pedagógicos construtivistas de Jean Piaget. O artigo examina as tentativas de transposição de teorias desses campos para os da prática educativa, ressaltando o caráter abstrato de prescrições que ignoram as práticas e os problemas característicos da cultura do trabalho escolar e dos princípios éticos e políticos que historicamente se associaram aos ideais da escolarização.

Palavras-chave: teoria e prática; teoria da educação; filosofia da educação

Is theory different in practice? Reflections on the relationship between theory and practice in educational discourses

Discussions concerning the relationship between theory and practice in teachers' preparation courses are a particular topic of a long lasting and wide subject, which may 
go as far back as the beginning of our philosophical tradition. In this article it is analyzed through the exam of two very influential models of pedagogical discourses: the first one which derives theories of education from the great philosophical systems and Jean Piaget's constructivist approach to education. The article analyses the attempts of transplanting theories from these two fields to educational practice, stressing the abstract character of its prescriptions and the problems which come up from the fact that they simply ignore the culture of everyday school work and its ethical and political basis.

Keywords: theory and practice; theory of education; philosophy of education

\section{La teoría es outra en la práctica? Consideraciones acerca de las relaciones entre teoría y práctica en los discursos educativos}

La cuestión de las relaciones entre la teoría y la práctica en la formación docente es un caso particular de un problema grande y complejo, cuyos esfuerzos de esclarecimiento se remontan al principio de la tradición filosófica. En este trabajo se enfocan dos tipos de discursos pedagógicos que ejerceran gran influencia en la formación docente en todo el siglo XX: las teorías de la educación pertenecientes a los grandes sistemas filosóficos y el discurso pedagógico constructivista de Jean Piaget. El articulo examina los intentos de adaptar las teorías a los campos de la práctica educativa, resaltando el carácter abstracto de las recetas que hacen caso omiso de las prácticas y los problemas propios de la cultura de trabajo de la escuela y de los principios éticos y politicos que históricamente han estado asociadas con los ideales de la educación.

Palabras clave: teoría y práctica; teoría de la educación; filosofia de la educación 
raro que, diante dos dilemas por ele inspirados, os discursos pedagógicos contemporâneos recorram a fórmulas retóricas vazias que não só pouco nos elucidam acerca da natureza dos problemas a enfrentar, como também impedem nossa reflexão sobre sua complexidade ou sobre a diversidade de formas por meio das quais o problema tem sido abordado. Por exemplo, é o que geralmente acontece quando, sob a alegação de uma recusa à dicotomia entre teoria e prática, se postula existir entre ambas uma "relação dialética". Claro que esse de fato pode ser o caso. No entanto, embora recorrente, tal adjetivação é insuficiente para a compreensão dessa relação, já que nada nos diz sobre sua natureza: seria a mesma, por exemplo, em campos tão distintos como o da medicina e o da política, da psicanálise e da educação? Esse tipo de recurso retórico generalizante não teria por efeito a anemia semântica do discurso e, por decorrência, a paralisia do pensamento?

Diante de um quadro como esse, saturado e paradoxalmente vazio, pode ser conveniente postular a pluralidade de formas pelas quais um saber teórico-proposicional (saber que) se relaciona com um saber operativo (saber fazer). Há casos em que a excelência no desempenho da prática pouco se relaciona com a posse ou o domínio prévio de uma teoria a ser "aplicada" em um contexto específico. Em que medida, por exemplo, a leitura de uma obra como $O$ riso: ensaio sobre a significação do cômico, de H. Bergson (1983), seria fundamental para o êxito ou aperfeiçoamento da prática de um comediante? Que papel pode ter uma "teoria do cômico" para aquele que deseja ser apenas engraçado? Haveria subjacente à prática do humor - prática inegavelmente intencional e inteligente, tal como o ensino - qualquer espécie de teoria, ou se trataria de um saber fazer não vinculado diretamente à posse de proposições teórico-conceituais? Ao mesmo tempo, não seria arriscado se submeter a uma cirurgia com um médico que desconhecesse completamente quaisquer proposições teóricas acerca da anatomia ou da fisiologia humana? No entanto, mesmo nesse caso, não é preciso reconhecer que a precisão de sua habilidade cirúrgica com o bisturi não deriva diretamente das "verdades teóricas" que tem em mente? ${ }^{1}$

Esse breve quadro de interrogações já basta para sugerir que qualquer reflexão acerca das relações entre teoria e prática que desconsidere a complexidade e a pluralidade de formas por meio das quais se vinculam corre o sério risco de veicular uma visão abstrata do problema. Mesmo reduzindo o escopo de investigação ao campo estrito das relações entre aportes teóricos e formação de professores, a variabilidade das relações e a complexidade de vínculos não permitem generalizações que possam ser abrangentes e elucidativas ao mesmo tempo. Por essa razão, a análise a seguir incidirá sobre as relações entre teoria e prática em duas modalidades específicas de

1 A esse respeito, ver Gilbert Ryle, The concept of mind (2002), especialmente o segundo capítulo, em que é analisada a distinção entre os usos proposicionais ("know that") e operativos ("know how to") do verbo "saber". 
discurso pedagógico muito influentes ao longo do século XX: a primeira, vinculada às grandes matrizes do pensamento filosófico (analisada na seção I), e a segunda, fundada na psicologia genética de inspiração construtivista (analisada na seção II).

Embora em declínio nos meios acadêmicos mais sofisticados, essas duas modalidades de discurso continuam exercendo significativa influência em programas de formação inicial e continuada de professores. Ademais, sua recente substituição por novas matrizes teórico-conceituais - como a "pedagogia das competências" não tem representado ruptura significativa em relação aos pressupostos e elementos estruturais que serão objeto de análise crítica nas considerações que se seguem. Ao contrário, a exemplo das teorias construtivistas, os discursos filiados à pedagogia das competências, na grande maioria, apresentam retórica prescritiva igualmente forjada em abstração da cultura escolar (das práticas pedagógicas e dos valores e princípios historicamente vinculados aos ideais da cultura letrada e da escolarização), sinalizando, assim, antes para uma continuidade acrítica do que para uma superação dos modelos precedentes.

O mesmo parece ocorrer com a recente transposição de expressões e conceitos oriundos de claudicantes teorias da administração de empresas para o âmbito dos discursos educacionais. Se suas prescrições parecem inócuas no que se refere à renovação das práticas escolares, sua difusão tem colaborado sistematicamente para o esvanecimento de qualquer sentido público para a formação educacional. Em sua perspectiva reducionista, a experiência escolar é concebida como mecanismo de conformação ao mercado de trabalho de uma sociedade consumista; a cultura do trabalho escolar, por sua vez, compreendida como algo análogo ao comércio de legumes. Não nos ocuparemos, contudo, dessas "novidades" do discurso educacional. Sua rápida evocação nesta apresentação visa apenas ressaltar o fato de que o núcleo dos problemas relacionados aos discursos pedagógicos que marcaram a segunda metade do século XX permanece intocado, a despeito da nova - mas talvez ainda mais frouxa - roupagem a vestir os modismos do discurso pedagógico contemporâneo.

\section{A FILOSOFIA COMO MATRIZ TEÓRICO-CONCEITUAL NA FORMAÇÃO DE PROFESSORES 2}

Até ao menos a segunda metade do século $\mathrm{XX}$, pode-se falar da presença marcante da filosofia nos discursos educacionais. De forma bastante sumária, poderíamos caracterizá-los como uma transposição, para o campo das teorias em educação, das diferentes visões metafísicas, ontológicas ou políticas, originalmente articuladas na obra de um pensador ou solidificadas, a partir de comentadores, em

2 Parte dos argumentos desenvolvidos nesta e na próxima seção foram detidamente examinados em Construtivismo: uma pedagogia esquecida da escola (Carvalho, 2001). 
um "sistema de pensamento" ou "doutrina filosófica". Falamos, por exemplo, de uma concepção de educação em Platão ou em Rousseau, porque neles é possível encontrar um conjunto articulado de reflexões sobre os ideais que devem reger os processos educativos, ainda que sempre subordinados às respectivas teorias políticas ou perspectivas acerca da natureza humana, da vida em sociedade, dos fundamentos da ética ou do conhecimento.

Esse gênero de discurso inspirou uma série de teorias da educação voltadas para a formação de professores. Nelas, procurou-se transpor e adaptar uma rede conceitual originariamente vinculada às grandes questões políticas, epistemológicas e éticas para o âmbito das preocupações teóricas e práticas da educação escolar. Tais tentativas, mais ou menos fiéis aos pensadores que as inspiraram, buscaram derivar de grandes sistemas filosóficos e conceituais algumas medidas práticas, como abordagens de ensino, ou mesmo perspectivas de políticas educacionais. Desse modo, forjaram um modelo influente de discurso pedagógico, vinculando o estabelecimento de objetivos e procedimentos da ação educativa a uma determinada visão de homem, valores e sociedade.

Em geral, os vínculos teóricos entre concepções filosóficas e um modelo específico de discurso pedagógico foram forjados por comentadores, pedagogos e teóricos da educação, ainda que em alguns casos importantes - como em John Dewey (1859-1952) e Immanuel Kant (1724-1804), por exemplo - os próprios filósofos tenham se encarregado desse tipo de articulação. Nessa modalidade de discurso educacional - ainda presente, embora em declínio -, postula-se que, a uma determinada concepção de homem, sociedade, conhecimento, deveria corresponder uma concepção de escola, aluno, avaliação etc. Em síntese, a cada grande "sistema" ou "teoria" sobre o "homem" corresponderia uma determinada "visão de educação", "deduzida" desse campo conceitual e de seus ideais éticos, políticos ou epistemológicos.

A despeito das enormes divergências teórico-conceituais, as diversas correntes que integram essa modalidade de discurso dividem um mesmo pressuposto: que é possível, a partir de concepções fundamentais de uma visão filosófica de homem, de sociedade e de ética, derivar ou mesmo "deduzir" uma concepção precisa de educação, e dela partir para doutrinas operativas e sugestões de práticas pedagógicas. A aceitação de tal pressuposto, contudo, exige cautelas. $\mathrm{O}$ argumento que parece sustentá-lo é o de que visões díspares desses aspectos engendram concepções e práticas educativas igualmente díspares. Assim, uma visão cristã de mundo, por exemplo, teria implicações educacionais radicalmente diferen-

3 Não se trata, como veremos adiante, de dedução no sentido canônico do termo. No entanto, não é raro seu emprego em discursos educacionais com o sentido de uma consequência retirada de um princípio. 
tes daquelas fundadas numa visão materialista. Poderíamos então inferir que, enquanto no primeiro caso, a instrução religiosa pode ser vista como elemento fundamental da formação ética, no segundo, essa ideia pode soar como estratégia de difusão de uma “ideologia”.

Ora, é inegável que certas concepções éticas, políticas ou epistemológicas, na medida em que apresentam um quadro do que é considerado importante e significativo na realidade, em seu conhecimento e na conduta humana, têm influência sobre, por exemplo, uma política curricular ou até sobre a aceitação ou rejeição de certas práticas pedagógicas. Mas, em geral, o que se postula é que haveria bem mais do que "alguma relação" entre essas diferentes visões filosóficas e as concepções e práticas educacionais. Kneller (1966) ilustra bem esse tipo de crença, ao afirmar que:

A filosofia educacional depende da filosofia formal porque quase todos os grandes problemas da educação são, no fundo, problemas filosóficos. Não podemos criticar os ideais e as diretrizes educacionais existentes, nem sugerir novos, sem atentar a problemas filosóficos de ordem geral, tais como a natureza da vida boa, que é um dos alvos da educação; a natureza do próprio homem, porque é o homem que estamos educando; a natureza da sociedade, porque a educação é um processo social; e a natureza da realidade suprema, que todo conhecimento procura penetrar [...]. O filósofo educacional pode estabelecer tais teorias deduzindo-as da filosofia formal e aplicando-as à educação. (p. 82)

Evidentemente, não se trata do caso isolado de um único autor. Pelo contrário, a ideia de que, a partir desses grandes temas, poderíamos “aplicar”, "deduzir" ou estabelecer linhas de atuação prática em educação é generalizada, inclusive em obras brasileiras de ampla penetração no campo da formação de professores. ${ }^{4}$ Como diferentes correntes teóricas elaboram distintas redes conceituais relativas a essas questões, a cada perspectiva teórica deveria corresponder uma "visão pedagógica". Assim, o professor, consciente ou inconscientemente, teria uma concepção de educação vinculada a certas visões filosóficas de homem, de sociedade e de conhecimento. A tarefa de uma "teoria da educação" seria oferecer aos professores modelos

4 A título de ilustração, poderíamos citar, nesse caso, a obra de Mizukami (1986), que procura apresentar um quadro geral das teorias de ensino e aprendizagem a partir de referenciais filosóficos ou científicos desses temas. Afirma a autora que: "O conhecimento humano, pois, dependendo dos diferentes referenciais, é explicado diversamente em sua gênese e desenvolvimento, o que, consequentemente, condiciona conceitos diversos de homem, mundo, cultura, sociedade, educação etc. [...] Diferentes posicionamentos pessoais deveriam derivar diferentes arranjos de situações de ensino-aprendizagem e diferentes ações educativas em sala de aula, partindo-se do pressuposto de que a ação educativa exercida por professores em situações planejadas de ensino-aprendizagem é sempre intencional. Subjacente a esta ação estaria - implícita ou explicitamente, de forma articulada ou não - um referencial teórico que compreendesse conceitos de homem, mundo, sociedade, cultura, conhecimento" (p. 3, grifos nossos). 
alternativos entre os quais ele optaria, orientaria e justificaria sua ação; portanto teorias educacionais sobre as quais sua prática se fundamentaria.

Contudo, o pressuposto incorre, em primeiro lugar, em grave equívoco do ponto de vista lógico. Não é possível "deduzir" de premissas metafísicas, ontológicas ou epistemológicas um curso necessário de ação ou prática educativa. Isso porque um processo de dedução depende inteiramente da manipulação formal de enunciados, e as conclusões que deles retiramos são fundadas, portanto, unicamente no que está de fato e literalmente expresso nas premissas. Com base no que é o homem não podemos "deduzir" como deve ser sua educação, a partir de uma teoria sobre o que é o conhecimento, não se pode deduzir como se deve ensinar, já que as conclusões propostas lançam mão de elementos ausentes nas premissas. Portanto, afirmar que de um conceito de homem podemos deduzir um programa educacional é uma falácia. O que é possível deduzir como princípio educacional de uma "visão materialista-dialética do mundo"? Os termos em que se expressam princípios políticos, ontológicos, éticos e epistemológicos são demasiadamente amplos para que deles se possa "deduzir" algo relativo às práticas educativas em contexto escolar.

Se não se trata de dedução, poderíamos então afirmar que tais posições "implicam", "condicionam" ou "têm como consequência" uma determinada abordagem prática do ensino ou da educação? Mesmo atenuando a expressão, o problema não se torna mais simples. Em que medida, por exemplo, apresentar a natureza humana como boa, mas corrompida pela vida social, pode implicar ou condicionar uma visão do que deve ser a prática educativa? Com a aceitação desse princípio axiológico, não poderíamos sugerir fins e procedimentos não só muito distintos, mas até conflitantes entre si? Não poderíamos, por exemplo, sugerir a extinção de qualquer tipo de escolaridade formal, dado o fato de que introduz os jovens em um mundo corrompido? Ou, então, sugerir que aprendessem desde cedo a conviver com esse mundo corrompido? Ou buscar educá-los para que se tornem felizes com a corrupção da própria natureza? Qualquer uma dessas perspectivas pode ser "derivada" ou considerada "consequência" do princípio metafísico inicial.

Princípios não carregam em si a regra de sua aplicação. Por isso, as práticas podem ser muito variadas e conflitantes, ainda que supostamente ancoradas nos mesmos fundamentos teóricos. Quantas escolas com procedimentos tão distintos professam a mesma fé inabalável nas "teorias construtivistas"? E, além disso, como explicar as desconcertantes semelhanças entre, por exemplo, as escolas da antiga Alemanha Oriental e as escolas conservadoras católicas, ambas supostamente fundadas em ontologias e visões de mundo opostas? O fato é que, assim como a adoção de uma ampla visão de mundo não implica uma prática pedagógica determinada, um mesmo conjunto de práticas escolares pode ter justificativas em perspectivas políticas, ontológicas ou metafísicas muito diferentes.

Como ressalta Scheffler (1978), os termos aos quais recorremos ao evocar como matriz essas grandes teorias sobre o homem ou o conhecimento são incapazes 
de isoladamente produzir quaisquer consequências práticas, pois precisam ser contextualmente suplementados por proposições programáticas de cunho prático, e o salto que vai da rede teórico-conceitual à ação é largo e arriscado, mesmo nos casos em que a teoria inicial venha a ser inegavelmente fecunda para a compreensão de aspectos relevantes da educação. Não se trata de negar a existência de qualquer impacto dessas modalidades de discurso nas práticas educacionais, mas de simplesmente tornar patente o fato de que os problemas educacionais têm especificidades cujo equacionamento exige muito mais do que uma "visão geral de mundo". A compreensão das peculiaridades históricas e sociais da educação escolar não pode ser lograda por simples analogias ou transposições de conceitos originalmente formulados sobre outros interesses teóricos; tampouco os problemas da prática educativa podem vir a ser interessantemente equacionados com base em perspectivas que ignorem a cultura das instituições escolares.

As discussões acerca da democratização da educação, marcantes a partir da segunda metade do século XX, ilustram de forma frisante os limites da transposição mecânica de conceitos e da aplicação acrítica de práticas de um campo social - a "política" em sentido estrito - a outro: as práticas pedagógicas de uma instituição escolar. A insistência - presente ainda hoje - em identificar a "democratização da educação" com a mera implantação de métodos pedagógicos e ritos de escolha, como assembleias e eleições, supostamente capazes de cultivar a liberdade do educando, tem resultado no empobrecimento tanto das discussões acerca do conceito de democracia como das que examinam seu vínculo com as práticas educacionais. Seja qual for o valor educativo dessas práticas, sua realização dentro do entorno escolar nunca ultrapassará o estatuto de simulacro de democracia; de faz de conta pedagógico (Azanha, 1986) no qual a liberdade interna da vontade individual é tomada como análoga à liberdade como fenômeno político. Nessa perspectiva, despolitiza-se a questão crucial da democratização do acesso a um patrimônio cultural público em favor de um ideal pedagógico de criação de relações interpessoais supostamente “democráticas" porque alegadamente "igualitárias".

É importante ressaltar que não se trata de um problema pontual e restrito à temática aludida. Ao contrário, esse exemplo, quase caricatural, deve ser tomado como ilustrativo de uma modalidade de discurso pedagógico no qual a apropriação dos resultados de uma investigação teórica é feita em abstração de seus processos, contexto e interesses. Não se busca, pois, um modo de pensar a especificidade do campo educação, mas uma forma de "aplicar" aos discursos e práticas pedagógicas os resultados de uma investigação teórica originariamente forjada a partir de outros campos e interesses. Nessa perspectiva, a filosofia deixa de ser um modo de interrogar a educação, com eventuais - embora sempre incertos - impactos em sua prática, para se constituir num suposto estoque de respostas a problemas que diferem substancialmente daqueles que lhe deram origem. Como veremos a seguir, a mera substituição da matriz teórica não implica a superação do modelo, podendo até mesmo agravá-lo. 


\section{A PSICOLOGIA DO DESENVOLVIMENTO COMO MATRIZ TEÓRICO- -CONCEITUAL NA FORMAÇÃO DE PROFESSORES}

O desenvolvimento das ciências humanas, ao longo dos séculos XIX e XX, impulsionou a esperança de que a aplicação de seus modi operandi ao campo da educação pudesse trazer inovações teóricas e práticas análogas às que então marcaram as investigações e práticas médicas. Já em 1911, Robert Rusk afirmava que: "quando os novos métodos de investigação [...] de educação experimental se tornarem generalizadamente aplicados e os resultados universalmente aceitos, deixar-se-á de impugnar à educação o direito de ocupar seu lugar entre as ciências" (Moraes, 1997, p. 21). No Brasil da década de 50, Fernando de Azevedo, ao inaugurar o CRPE-SP, afirmava que naquele momento tinha início uma nova era, na qual "o empirismo, a improvisação e a superficialidade cedem, afinal, o lugar ao espírito e aos métodos científicos nos estudos dos problemas da educação" (Ferreira, 2001, p. 84).

Em meio a esse entusiasmo cientificista, as psicologias da aprendizagem e do desenvolvimento passaram a ocupar lugar privilegiado no campo, alternando-se desde então nos modismos do jargão pedagógico. $\mathrm{O}$ construtivismo piagetiano, por sua marcante presença no Brasil, é um exemplo particularmente interessante dessa modalidade de discurso pedagógico, que pretende, a partir de investigações de cunho psicológico, nortear a produção teórica e as orientações práticas em educação. Nele, objetivos educacionais e procedimentos didáticos subordinam-se a uma teoria do desenvolvimento cognitivo e a uma concepção de infância e aprendizagem que arroga para si o estatuto de investigação científica supostamente capaz de imprimir às teorias e práticas educacionais um novo estatuto epistemológico e um novo desenvolvimento técnico. Em sua obra Psicologia e pedagogia, Piaget deixa expressa essa sua crença na capacidade de "progresso" técnico e científico da educação a partir de investigações empíricas acerca das controvérsias que marcavam - e marcam - o campo da educação diante da urgência de suas escolhas:

É um problema da pedagogia experimental decidir se a melhor maneira de aprender a ler consiste em começar pelas letras, passando em seguida às palavras e finalmente às frases, segundo preceitua o método clássico chamado analítico, ou se é melhor proceder de forma inversa, como recomenda o método "global" de Decroly. Só o estudo paciente, metódico, aplicado aos grupos comparáveis [...] é capaz de permitir a solução do problema. (Piaget, 1978, p. 34)

Assim, o recurso a procedimentos canonizados no âmbito das ciências é concebido como a forma mais adequada de orientar as escolhas práticas em educação. Ao fornecer dados sistematicamente submetidos a testes, poderiam apontar a melhor maneira, por exemplo, de alfabetizar. É preciso ressaltar, no entanto, que uma pesquisa dessa natureza, se viável, poderia apontar o método supostamente mais eficaz, rápido ou fácil, o que não necessariamente tem a ver com o melhor na 
perspectiva de uma formação educacional. É evidente que a eficácia, a facilidade ou a rapidez podem ser critérios importantes para a adoção de um método de trabalho escolar. No entanto, podem não ter a primazia numa escolha que, por seu caráter formativo e não meramente instrumental, envolve uma série de outros valores e princípios. Esse é o caso da alfabetização, se a concebermos não apenas como capacidade ou competência técnica, mas como forma de iniciação na cultura letrada. Por isso, rapidez, eficácia e mesmo facilidade não são critérios absolutos e também devem ser julgados à luz dos ideais formativos da escolarização pública.

Basta lembrar, nesse sentido, de escritos como A República, ${ }^{5}$ de Platão, para pelo menos pôr em dúvida essa ideia, tão alegre e acriticamente aceita, de que, em educação, o caminho mais simples e fácil coincide sempre com o "melhor" do ponto de vista formativo. É perfeitamente defensável que, embora mais lenta e difícil, uma forma de trabalho venha a ser adotada em função de outros valores que consideremos superiores, como o "esforço pessoal" ou mesmo a "disciplina" para o trabalho intelectual.

Em educação, a escolha das formas de trabalho sempre exige a articulação de vários princípios institucionais de natureza formativa, ética e política, que podem inclusive entrar em conflito entre si. Tais princípios não são passíveis de ser "testados" como "hipóteses", pois não se referem à "verdade" ou "falsidade" de uma tese, mas ao significado educativo de certas práticas docentes. Podemos, por exemplo, crer que a própria autonomia dos professores na escolha de determinado modo de trabalho seja um valor mais importante a cultivar no contexto da formação educacional do que a suposta eficácia de uma forma de trabalho ou de um material padronizado. Trata-se, nesse caso, não de uma hipótese a ser verificada, mas de um julgamento e de uma escolha que podem ser racionalmente justificados e debatidos, mas não cientificamente testados.

Jamais será apenas com base em dados empíricos que poderemos justificar, por exemplo, a pertinência da adoção de uma política que favoreça ou dificulte o acesso de certos segmentos ou da totalidade da população à escolaridade fundamental; e o mesmo poderia ser apontado quanto à definição dos mecanismos de avaliação e seletividade dentro desse sistema educacional ou mesmo das escolhas curriculares. Estas, como a maior parte das questões educacionais, remetem a decisões de ordem programática, cujos critérios de avaliação e escolha podem contar

5 A descrição da ascese da vida na caverna à contemplação última do sol, presente no Livro VII, mostra o processo formativo não como simples e fácil, mas como uma árdua tarefa espiritual. Nela, o prisioneiro a ser liberado das ilusões é forçado a sair, a responder perguntas, a olhar a luz; o caminho é descrito como rude e ingreme; e considera-se natural que, em sua subida, ele se doesse e agastasse (Cf. A República, 515a a 516 a). Não se trata, a nosso ver, de uma concepção rara naquele contexto. Em Antígona, de Sófocles, é antológica a passagem em que o coro afirma que nada de grande entra na alma humana sem sofrimento. 
com o auxílio de investigações empíricas, mas necessariamente as ultrapassam, porque visam ao estabelecimento de objetivos e ao esclarecimento e à veiculação de conceitos e programas de ação. São, portanto, decisões de cunho ético e político e não técnico-científico.

Um dos escritos de Piaget sobre o ensino de história pode ilustrar os limites incontornáveis da pretensão de renovar a produção teórica e as orientações práticas da educação com base em teorias psicológicas. Em artigo acerca das possíveis contribuições da psicologia da criança para esse campo do ensino, ${ }^{6}$ Piaget propõe-se a oferecer aos pedagogos os resultados de pesquisas iniciais sobre como a criança representa o passado não vivido. A partir da apresentação de dados sobre o desenvolvimento das representaçôes espontâneas (!) da história na criança, o autor comenta brevemente sua importância para eventual uso pedagógico:

[...] as primeiras reações que notamos em nossos sujeitos não são simplesmente o reflexo de conhecimentos escolares mal digeridos: elas testemunham uma atitude especificamente pueril na presença do passado. $O$ passado infantil não é nem longínquo nem ordenado em épocas distintas. Ele não é qualitativamente diferente do presente. A humanidade permanece idêntica a si mesma, tanto em sua civilização como em suas atitudes morais. E, sobretudo, o universo é centrado no país ou na cidade a que pertence o sujeito. Reencontramos, assim, o egocentrismo no domínio histórico, tal como existe em todas as representações da criança. Abstenhamo-nos, evidentemente, de retirar dessas esparsas investigações toda uma pedagogia. Mas se verdadeiramente [...] a educação do sentido histórico da criança supõe a educação do espírito crítico ou objetivo, a da reciprocidade intelectual e a do senso de relações ou de escalas, nada nos parece mais próprio para determinar a técnica de ensino da história que um estudo psicológico das atitudes intelectuais espontâneas da criança, por mais ingênuas e negligenciáveis que elas possam parecer de início. (Piaget, 1998, p. 95)

Para os propósitos desta discussão, deixemos de lado uma série de questões conceituais e empíricas que mereceriam análise do ponto de vista psicológico ou antropológico, como o postulado caráter "natural" ou "racional" da linearidade e da progressividade na representação do tempo histórico. Para as análises relativas a seu emprego educacional, podemos supor que os resultados apresentados acerca da construção da temporalidade e da reciprocidade sejam plenamente aceitáveis. Ainda assim, o fato é que as supostas fases e estruturas desenvolvidas pelas crianças na construção da noção de "passado" podem, no máximo, explicar limites e possibilidades gerais das estruturas cognitivas na compreensão desses fenômenos. Elas

6 "Psychologie de l'énfant et enseignement de l'histoire", apresentado por Piaget na Conferência Internacional para o Ensino de História, em 1933, em Genebra, e publicado na coletânea De la pédagogie (1998, p. 97-104). 
podem mostrar ao professor, por exemplo, que é perfeitamente normal que uma criança de determinada faixa etária não tenha clara noção sequencial dos eventos ou ainda projete para o passado certas características do presente. No entanto, o conjunto principal de problemas que um professor deve enfrentar ao estabelecer prioridades, conteúdos, formas e objetivos do ensino de história em uma instituição escolar permanece intocado.

Os dados e objetivos apresentados por Piaget, por exemplo, são absolutamente compatíveis com um ensino de história que se concentre em grandes eventos e heróis, no cotidiano de civilizações passadas ou na dialética das transformações dos modos de produção. Seria também compatível com um ensino de história que procurasse forjar no aluno uma identidade nacional ou modelos de comportamento exemplares. Para a prática escolar, no entanto, trata-se exatamente de escolher entre perspectivas mutuamente excludentes. $\mathrm{O}$ mesmo poderia ser apontado em relação às civilizações ou eventos históricos que devem integrar determinado currículo: devemos ou não incluir em um programa escolar específico, por exemplo, a história dos povos africanos e das nações indígenas pré-colombianas? E o mesmo ainda poderia ser dito em relação às formas pelas quais tais eventos serão apresentados, estudados ou avaliados pelo professor.

Cada uma dessas decisões teóricas ou práticas está impregnada de antecedentes e consequências educacionais, e seria pouco sensato sustentarmos que, como todas são compatíveis com a natureza e o curso do desenvolvimento das noçôes de história, cumprem igualmente seu papel educativo ou têm pouca importância para a visão de história que será elaborada pelo aluno que com elas interage. Por outro lado, como vimos, não é possível, a partir da descrição da natureza do desenvolvimento espontâneo da noção de história, deduzir ou derivar decisões fundamentais sobre conteúdos, metas e formas de ensino.

Enfim, o ensino de história em uma instituição escolar - como o de qualquer disciplina, capacidade, hábito ou valor - exige do professor escolhas relativas ao conteúdo a ser abordado; à perspectiva na qual será abordado; às formas pelas quais tais informações e o próprio modo de pensar a história serão apresentados e ainda decisões quanto aos objetivos da disciplina no contexto específico de uma instituição escolar e seus grupos. Por isso, as responsabilidades e metas do professor e da escola ultrapassam largamente, embora possam incluir, o desenvolvimento psicológico da noção de temporalidade ou mesmo da reciprocidade intelectual.

Esses objetivos, perspectivas, procedimentos e formas de ensino só podem encontrar modelo, justificação e compreensão na própria cultura das instituiçốes escolares, nas peculiaridades de cada grupo social que a ela pertence, enfim, no fato de que, como destaca Azanha,

[...] a escola, ou melhor, o mundo escolar é uma entidade coletiva situada num certo contexto, com práticas, convicções, saberes que se entrelaçam numa his- 
tória própria e em permanente mudança. Esse mundo é um conjunto de vínculos sociais frutos da aceitação ou da rejeição de uma multiplicidade de valores pessoais e sociais. (Azanha, 2006, p. 103)

Assim, a concepção de educação que tenha como objetivo o pleno desenvolvimento das capacidades psicológicas das crianças e dos jovens parece ignorar ou menosprezar o "mundo escolar" no qual se dará o ensino de qualquer disciplina. Por isso, quando aplicada às instituições escolares, torna-se também ela uma visão exterior e abstrata dessas instituições: o desenvolvimento das capacidades é visto em abstração dos conteúdos escolares específicos; a aprendizagem do aluno, em abstração do ensino e das escolhas do professor; o desenvolvimento do jovem, em abstração das condições e dos valores sociais específicos de uma sociedade historicamente determinada.

Como decorrência desse caráter abstrato, as recomendações de procedimentos didáticos e educacionais do construtivismo pedagógico raramente têm resultado em alternativas de práticas escolares que sejam simultaneamente operacionalizáveis e significativas. Ao contrário, frequentemente transformados em slogans e palavras de ordem, seus princípios didáticos e orientações metodológicas raramente ultrapassam fórmulas gerais de escasso valor prático para o trabalho do professor. E nem poderia ser de outro modo.

O que se espera de um discurso que almeje modificar um conjunto de práticas sociais historicamente solidificadas, como as escolares, é que as descreva e as compreenda em suas manifestações mais típicas ou frequentes, em seus condicionantes e resultados e, a partir disso, aponte alternativas e as justifique, levando em consideração os valores e condicionantes históricos associados. O construtivismo educacional, no entanto, tem pretendido levar a cabo reformas educacionais com base no conhecimento psicológico de um dos polos envolvidos nessa relação: a criança que educamos, como se a mera posse das informações acerca de seu desenvolvimento cognitivo pudesse condicionar as práticas pedagógicas, as escolhas curriculares e demais decisões inerentes à complexidade de qualquer proposta educacional. Assim, o construtivismo pedagógico parece postular que as práticas escolares seriam decorrentes dos conceitos de criança, inteligência, desenvolvimento etc., de forma que a renovação desses conceitos nas representações dos professores teria como resultado a renovação de suas práticas. ${ }^{7}$

Ora, como vimos, essa postulada relação entre concepções teóricas de professores e suas práticas escolares é bastante frágil. Entre outros fatores, porque concebe as transformações nas práticas educativas como decorrência da posse de novos conceitos e princípios, ignorando que todo conceito ou máxima é inevitavelmente uma proposição com certo grau de generalidade que não pode conter especificações que a adapte aos detalhes de um fato particular. Como lembra Ryle, "um soldado não

7 Ver, por exemplo, Fernando Becker (2006). 
reagem aos atos, processos e técnicas a que são submetidos, independentemente de quem os opera. Daí por que a substituição de um operário não altera significativamente o produto industrial: a tecnologia decreta a superfluidade do trabalhador, de sua experiência e singularidade. Mas as pessoas - sobretudo os alunos em formação - não reagem somente às técnicas, aos métodos e procedimentos a que são submetidas. Reagem também e fundamentalmente à singularidade da pessoa que as ensina, à sua visão de mundo; reagem, portanto, não somente àquilo que um professor faz, mas a quem ele é. Daí que o processo formativo de um professor não se esgota no desenvolvimento de suas "competências profissionais", mas inclui necessariamente a formação de um sujeito. A menos que se tenha por objetivo a decretação da superfluidade do educador.

\section{REFERÊNCIAS}

Arendt, Hannah. Between the past and the future. 10. ed. Nova York: Penguin, 2006. AzAnHA, José M. P. Educação: alguns escritos. São Paulo: Cia. Editora Nacional, 1986. . A formação do professor e outros escritos. São Paulo: SENAC, 2006.

Becker, Fernando. A epistemologia do professor: o cotidiano da escola. Petrópolis: Vozes, 2006.

Bergson, Henry. O riso: ensaio sobre a significação do cômico. Rio de Janeiro: Jorge Zahar, 1983.

Carvalho, José S. F. Construtivismo: uma pedagogia esquecida da escola. Porto Alegre: Artmed, 2001.

KNELLER, George. Introdução à filosofia da educação. Rio de Janeiro: Zahar, 1966.

Mizukami, Nicoletti. Ensino: as abordagens do processo. São Paulo: EPU, 1986.

Moraes, Amaury C. Uma crítica da razão pedagógica. Tese (Doutorado em Educação) Faculdade de Educação, Universidade de São Paulo, São Paulo, 1997.

Piaget, Jean. Psicologia e pedagogia. São Paulo: EPU, 1978.

. Sobre a pedagogia. São Paulo: Casa do Psicólogo, 1998a.

. De la pedagogie. Paris: Odile Jacob, 1998b.

Platão. A República. Tradução Maria Helena da Rocha Pereira. 5. ed. Lisboa: Gulbenkian, 1987.

RYLE, Gilbert. The concept of mind. 2. ed. Chicago: UCP, 2002.

SAnTos, Márcia Ferreira. Centros de Pesquisa do INEP: pesquisa e política educacional entre as décadas de 1950 e 1970. Dissertação (Mestrado em Educação) - Faculdade de Educação, Universidade de São Paulo, São Paulo, 2006.

SCHeffler, Israel. A linguagem da educação. São Paulo: Saraiva; EDUSP, 1978. 


\section{SOBRE O AUTOR}

José Sérgio F. DE CARvalho é doutor em filosofia da educação pela Universidade de São Paulo. Professor do Programa de Graduação e Pós-Graduação da mesma instituição.

E-mail: jsfcusp@usp.br 